\title{
Regenerative medicine: potential applications for foot and ankle disorders
}

\author{
Francesco Caravaggio ${ }^{1,2}$, Michele Antonelli ${ }^{3}$, Fabio Depalmi ${ }^{1,2}$ \\ ${ }^{1}$ Center for Foot and Ankle Surgery, "Casa di Cura Città di Parma," Parma, Italy; ${ }^{2}$ "G. \\ Pisani Ex-Alumni" Association, Verduno, Italy; ${ }^{3}$ Public Health Service, AUSL-IRCCS \\ Reggio Emilia, Italy
}

\begin{abstract}
SUMMARY
Introduction. Regenerative therapies have recently gained popularity in orthopedics and we overview the available scientific evidence on the topic.

Methods. A narrative literature review with three relevant case reports.

Results. Scientific evidence on regenerative medicine is growing, but some established findings can de underscored. First, a persistent inflammatory response plays a key role in tissue reparation because it inhibits the activity of stem cells: therefore, regenerative therapy is effective if it can reduce local inflammation, thus allowing stem cells to regenerate the damage. Secondly, the regenerative potential of stem cells is regulated by local immunity and, in particular, by macrophages, which are involved in damage response and tissue regeneration. Among others, the concentrate of peripheral blood mononuclear cells (PBMNCs), rich in monocytes, lymphocytes, and CD34+ hematopoietic stem cells, appears an interesting cell-based therapeutic strategy to promote tissue regeneration in several orthopedic disorders.

Discussion. Regenerative medicine can offer new valuable therapeutic strategies. In particular, potential applications of PB-MNCs in foot and ankle disorders are discussed with some explanatory cases from clinical practice.
\end{abstract}

Accepted: July 5, 2021

Correspondence

Francesco Caravaggio

Center for Foot and Ankle Surgery, "Casa di Cura

Città di Parma", Piazzale Athos Maestri 5, 43123

Parma, Italy. E-mail: dott.caravaggio@tin.it

How to cite this article: Caravaggio F, Antonelli M, Depalmi F. Regenerative medicine: potential applications for foot and ankle disorders. Lo Scalpello Journal 2021;35:117-128. https://doi. org/10.36149/0390-5276-208

(C) Ortopedici Traumatologi Ospedalieri d'Italia (O.T.O.D.I.) 2021

\section{(c) (i) () $\Theta$}

This is an open access article distributed in accordance with the CC-BY-NC-ND (Creative Commons Attribution-NonCommercial-NoDerivatives 4.0 International) license. The article can be used by giving appropriate credit and mentioning the license, but only for non-commercial purposes and only in the original version. For further information: https://creativecommons.org/licenses/by-nc-nd/4.0/deed.en
Key words: regenerative medicine, mononuclear cells, limb ischemia, tendinopathy, muscle lesion

\section{Introduction}

Recently, regenerative therapies have gained popularity as cutting-edge therapeutic strategies in both orthopedics and other medical specialties. Some of these therapies imply the use of cells derived from specific tissues (e.g. cartilage), first expanded in vitro and then implanted in specific body areas involved by the disease; regenerative tissue scaffolds frequently associated with platelet gel; bone marrow or fat tissue (nano fat grafting or stromal vascular fraction). Since these treatments are usually expensive, the risk of an inappropriate extension of their clinical indications under the pressure of economic interests cannot be fully excluded. Therefore, we overviewed the available evidence on the topic.

In the scientific literature, there is more than one definition of regenerative medicine:

- regenerative medicine can encompass all interdisciplinary activities, both clinical and research-related, aimed to repair and regenerate damaged cells and tissues;

- regenerative medicine is a branch of medicine whose ultimate purpose is to 
repair damaged cells, tissues and organs by regenerating (rather than substituting) them.

Regenerative medicine is based on innovative therapeutic techniques, including cellular therapy, stem cell implantation, cellular reprogramming and tissue engineering. In particular, tissue engineering was first invented by Eugene Bell at the Massachusetts Institute of Technology and is defined as a branch of regenerative medicine which studies how to regenerate, preserve, improve or heal a damaged tissue by properly assembling some particular functional constructs.

\section{Materials and methods}

Since relevant scientific evidence is rapidly evolving and regenerative medicine is not yet a well-structured discipline, we performed a narrative literature review to provide the reader with a streamlined, cutting-edge and practical overview, combining current evidence with the authors' experience and considerations. The search was performed by two reviewers (F.C. and F.D.) in PubMed/Medline and Google Scholar using the following keywords: "Regenerative Medicine", "stem cell*", "Peripheral Blood Mononuclear Cell*", "macrophage polarization", "bone*", "tendon*", "muscle*", "cartilage*”, "critical limb ischemia", and "diabetic foot". Then, retrieved evidence was synthetized and critically discussed. In order to offer some useful practical examples, three relevant case reports were described along with the qualitative synthesis of existing evidence. Full informed consent was obtained from each patient on a voluntary basis. Clinical data and images were completely anonymized, privacy protection was guaranteed in accordance with EU and Italian regulations, and strict confidentiality was ensured, thus avoiding any stigma or harm to involved subjects.

\section{Tissue regeneration and its phases}

\section{Tissue regeneration}

All living beings have the potential to regenerate parts of their bodies and this ability varies from species to species, being inversely correlated with bio-physiological complexity of each organism: for example, mammals progressively experience a reduction in their regenerative potential after the first years of life. Equally, the regenerative capacity of diverse organs and tissues is different even within the same species. The cornerstone of any tissue regenerative capacity is the stem cell, which can generate other stem cells or cells with different characteristics. After an asymmetric cell division, any stem cell can produce another stem cell and a progenitor, from which a mature differentiated cell of a specific tissue will originate. Among stem cells, it is possible to identify the following cell types:

- Embryonic Stem Cells (ESCs): are pluripotent and derive from the embryo before germ layers develop;
- Tissue or Adult Stem Cells (ASCs): can be found in an adult or fetal tissue and have the potential to only differentiate into cells of that specific tissue (e.g. hematopoietic stem cells or HSCs, which can give origin to all blood cells);

- Induced Pluripotent Stem Cells (IPSCs): originate from ASCs and regain their pluripotency through genetic manipulation.

Current scientific knowledge underscores the fundamental role of the immune system in regulating tissue regeneration: in particular, macrophages and lymphocytes can promote healing processes in a damaged tissue thanks to their capacity to influence the inflammatory micro-environment in such a way as to allow regeneration ${ }^{1,2}$. Monocytes/macrophages and regulatory $\mathrm{T}\left(T_{r e g}\right)$ lymphocytes can modulate the activity of local stem cells in both physiological and in pathological conditions ${ }^{3}$.

Moreover, monocytes and macrophages, found in all body tissues, form a cell population with different functions and phenotypes, and can therefore regulate local homeostasis in various ways. With regards to phenotypic modifications associated with specific functions, mononuclear phagocytes can be categorized into two groups ${ }^{4}$ :

- M1, which are involved into initial stages of the response to tissue damages, with a pro-inflammatory and degenerative role;

- M2 (further divided into two subgroups), which have anti-inflammatory properties and can regulate the reparative-regenerative stage ${ }^{4}$.

\section{Phases of tissue regeneration}

If we consider wound healing, two fundamental phases can be identified:

1. the inflammatory phase, which is necessary to circumscribe the lesion and remove damaged tissues: lesion-induced hypoxia can stimulate endothelial, stromal and white cells to release granulocyte-macrophage colony-stimulating factor (GM-CSF), with consequent attraction of circulating monocytes and activation of local macrophages. These leucocytes can produce cytokines, chemokines, growth factors, inflammatory mediators, and can also phagocytize damaged tissues, "non-self" substances, and microorganisms ${ }^{5}$. Fundamental mediators released by these white cells are interleukin-1 (IL-1) and tumor necrosis factor (TNF- $\alpha$ ). The inflammatory phase tends to markedly decline 3 to 4 days after the injury.

2. the proliferative phase, which follows the inflammatory phase. M1-like macrophages are converted into M2-like polarized macrophages (repair function), which become prevalent at 7 to 8 days after the injury ${ }^{6}$.

M2-like macrophages can:

- release growth factors ${ }^{2,5}$;

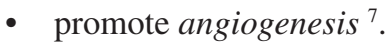

- activate local stem cells through exosomes and nano-vesicles ${ }^{8,9}$. 
Regardless of the specific cause, whenever inflammation persists in injured tissues, regenerative processes are hindered or even inhibited.

\section{Regenerative therapies}

First of all, regenerative therapies should switch off inflammation to indirectly favor regenerative processes promoted by local stem cells: in fact, it has been demonstrated that chronic inflammation can reduce the regenerative potential of these cells ${ }^{10}$. Some new therapeutic strategies involve the modulation of the immune system function, thus improving the local recruitment of macrophages and their polarization from M1 to M2, with the ultimate aim to increase the activation of local stem cells ${ }^{11}$. Recent autologous therapeutic strategies can be divided into two categories: non-cellular therapies (growth factors) and cell therapies.

\section{Non-cellular therapies}

Among non-cellular therapies, platelet-rich plasma (PRP), first proposed in the 1980's, is probably the most popular. PRP is obtained from venous blood, after centrifugation, and includes platelets (namely cytoplasmic fragments of megakaryocytes) capable of releasing growth factors (PDGF, VEGF, TGF- $\beta$, EGF), or serum and plasma in which platelets have already released these substances. When evaluating the therapeutic activity of PRP, it appears that anti-inflammatory effects prevail over regenerative ones. In a recent meta-analysis by Franchini et al., the efficacy of PRP was rated as "marginal", and it was concluded that, to date, PRP is not supported by strong evidence in orthopedics, thus recommending further randomized controlled trials to thoroughly assess its potential indications, long-term beneficial effects, and cost-benefit ratio ${ }^{12}$.

\section{Cell therapies}

Cell therapies are various, and some are difficult to source and apply because they require cellular expansion in authorized cell factories. Among cell therapies, it is worthwhile to mention the following:

- Bone marrow-derived mesenchymal stem cells (BMMSCs). In bone marrow, stem cells are mostly hematopoietic (HCS), and, although only to a small extent, even mesenchymal (MSC). Regenerative techniques involving these cells imply that the sample is sent to dedicated laboratories for in vitro cellular expansion: critical issues are the necessity to maintain the cell sample sterility throughout the entire process and to purify the final product from all cytokines used to promote in vitro cell replication. Extensive and complicated cell manipulations in specialized laboratories, as well as the fact that this is a two-step procedure (bone marrow sampling followed by implantation of stem cells) explain its high costs.
- Adipose tissue-derived mesenchymal stem cells (ATMSCs). After liposuction, cells are enzymatically extracted from the sample and then expanded in vitro ${ }^{13}$. It is interesting to notice that the number of mesenchymal cells obtained from a concentrate of adipose tissue is 500 times higher than the quantity of mesenchymal cells derived from the same amount of bone marrow ${ }^{14}$. However, in vitro experiments showed that AT-MSCs may have a lower chondro-genetic potential compared with bone marrow-derived stem cells ${ }^{15}$ and the techniques involving the use of AT-MSCs still require two steps. Other concentrates can be directly obtained in operating/surgical theaters with pointof-care systems.

- Bone marrow aspirate concentrate (BMAC). It is obtained from the iliac crest, sampled in an operating theater and then centrifuged: the concentrate is rich in bone marrow-mononuclear cells (BM-MNCs), but also includes other cell types, such as granulocytes, lymphocytes, erythrocytes, platelets, CD34+ (hematopoietic) stem cells (1.5$1.9 \%$ ), and MSCs (0.01-0.03\%) with their specific concentration varying on the basis of the device used ${ }^{16}$. Since the procedure required to prepare the BMAC is invasive, its repeatability over time in the same patient is not easy to achieve, and, moreover, recent studies have concluded that, in order to obtain better clinical outcomes in subjects with critical lower limb ischemia, the frequency/number of implants is more important than the quantity of cells transplanted in every single procedure ${ }^{17}$.

- Adipose-derived stromal vascular fraction (AD-SVF). All marketed systems for a direct intra-operatory use involve nano-grafts of AD-SVF extracted through centrifugation or filtration of a lipo-aspirate. The AD-SVF is composed of a heterogeneous population of cell types, including pericytes, endothelial cells, smooth muscle cells, fibroblasts, macrophages, and MSCs, which markedly vary on the basis of adipose tissue sampling site ${ }^{19,20}$.

- Peripheral blood mononuclear cells (PB-MNCs). These are obtained by filtration of an anticoagulated sample of peripheral blood (100-120 mL). This system shares a high selectivity for monocytes, lymphocytes, and CD34+ cells ${ }^{21}$. At the present state of knowledge, this autologous regenerative technique appears quite promising, especially if we consider that monocytes/macrophages and $\mathrm{T}_{\text {reg }}$ lymphocytes play a central role in tissue regeneration and in the activation of MSCs. To date, the clinical efficacy of PB-MNC concentrates has been studied for the treatment of critical limb ischemia in no-option patients, for whom it has been demonstrated to be the only autologous cell therapy capable of reducing major amputations ${ }^{22-24}$. This technique has also been used for patients with diabetic foot ${ }^{25-28}$ or, in general, with chronic lesions ${ }^{29}$. Considering the mechanism of action of this therapeutic technique, its use has therefore been extended to selected orthopedic illnesses. 


\section{Clinical applications}

\section{Bone regeneration}

Monocytes/macrophages substantially and lengthily contribute to healing processes of bone fractures, thus regulating the homeostasis of bone tissues by releasing interleukins (IL-1 and IL-6), oncostatin M, bone morphogenetic protein (BMP), and angiogenetic factors like vascular endothelial growth factor (VEGF) and nitric oxide (NO) ${ }^{30-35}$. These osteotrophic substances can activate local MSCs, thus favoring osteogenesis and stimulate the secretion of bone mineralization-promoting mediators such as alkaline phosphatase and type 1 collagen. Monocytes/macrophages, through several molecular pathways and elaborated intercellular cross-talk, can also stimulate other cells to produce cytokines capable of promoting bone regeneration ${ }^{10,36,37}$. This complex network of cellular cross-talk is currently studied by a specialized discipline called osteo-immunology ${ }^{38}$.

To further underscore the key role of the immune system in bone regeneration, Henrich et al. have demonstrated that a bone lesion cannot be regenerated when injected with a monocyte-free bone marrow concentrate, whereas regenerative processes can be observed if stem cells are eliminated from the concentrate, thus highlighting that monocytes (but not stem cells) have an osteoinductive capacity ${ }^{39}$. Additionally, macrophages can regulate the recruitment and differentiation of MSCs ${ }^{10,43-46}$, and recent evidence suggests that cell polarization from M1-like to M2-like macrophages is essential for bone regeneration ${ }^{47}$. Finally, it has been observed that even $\mathrm{T}$ and B lymphocytes contribute to bone regeneration because they can induce release of BMP-2, modulate cell differentiation, promote bone mineralization, and restore local homeostasis after infiltrating the callus ${ }^{40-42}$.

\section{Tendon regeneration}

Tendon diseases can be caused by acute trauma or, more often, by overuse or chronic stress which usually result in characteristic degenerative alterations of tendon tissues. The majority of tendons are surrounded by a layer of epithelial cells which can turn into a source of fibroblasts in case of damage. In fact, under certain conditions, epithelial cells can trans-differentiate into fibroblasts and regenerate the damaged extracellular matrix (ECM). This process usually starts with the activation of a signaling pathway called "Epithelial-to-Mesenchymal Transition" (EMT): changes in the macrophage phenotype along with downstream pathways triggered by the EMT can, in the first place, contribute to the degradation of damaged tissues and, after that, to subsequent repairing processes of a tendon ${ }^{48}$. In particular, it has been observed that an acute tendon injury can potentially evolve into a chronic disease and, even if to date there is no clear explanation, it is plausible to hypothesize a causal association with locally persistent chronic inflammation ${ }^{49,50}$.

Inflammation in damaged tendons is characterized by the infiltration of immune cells like neutrophils and macrophages. The balance between cells with pro- and anti-inflammatory properties (M1/M2) and release of soluble factors capable of influencing wound healing can have a marked impact on the outcome of the inflammatory process: deregulation or poorly effective modulation of such processes can lead to chronic inflammation and fibrosis. The polarization of M1/M2 macrophages can play a role in it, since the long-lasting prevalence of M1-like macrophages with pro-inflammatory properties can increase the chance of acute damage to evolve into a chronic tendinopathy. Therefore, the injection of circulating autologous monocytes, which favor M1/M2 macrophage polarization may be a valuable cell therapy for healing promotion of damaged or degenerated tendons ${ }^{51}$.

Case report 1: regenerative therapies for a tendon injury This case report describes the use of autologous PB-MNCs in the treatment of a tendon lesion (Fig. 1).

Patient's general characteristics: male, 62 years old, active lifestyle (amateur sportsman - triathlon).

History: the patient, with no relevant comorbidities, complained of a progressively worsening pain in his right ankle. The pain was severe enough to force him to interrupt any physical activity. The subject did note report taking any medicinal drug and did not recall any major trauma in his recent history. Diagnosis, treatment and outcome: after clinical assessment and NMR examination, the patient was diagnosed with a traumatic-like lesion (probably due to long-lasting functional overload) extending to up to the $50 \%$ of the right Achilles tendon accompanied by an asymptomatic bilateral tendinosis of both Achilles tendons (Fig. 1A). Therefore, with the patient's informed consent, it was decided to opt for injection of autologous PB-MNCs and to fully interrupt any sports activity for 2 weeks. Then, from the third week on, it was recommended to do eccentric physical exercises twice a day, and, among sports activities, only swimming and cycling. Local pain disappeared at one month after intervention and, at the 2-month follow-up visit, NMR showed full recovery of the tendon lesion, even if with a persistent background tendinosis (Fig. 1B). The subject started again with his amateur sports activity without any other right Achilles tendon symptomatology.

\section{Muscle regeneration}

The potential regenerative role of monocytes, macrophages and lymphocytes has been extensively described in the scientific literature ${ }^{52-58}$. Juban et al. have demonstrated that, after muscle injury, circulating monocytes can reach the lesion and turn into M1-like macrophages, which stimulate myogenic cell 


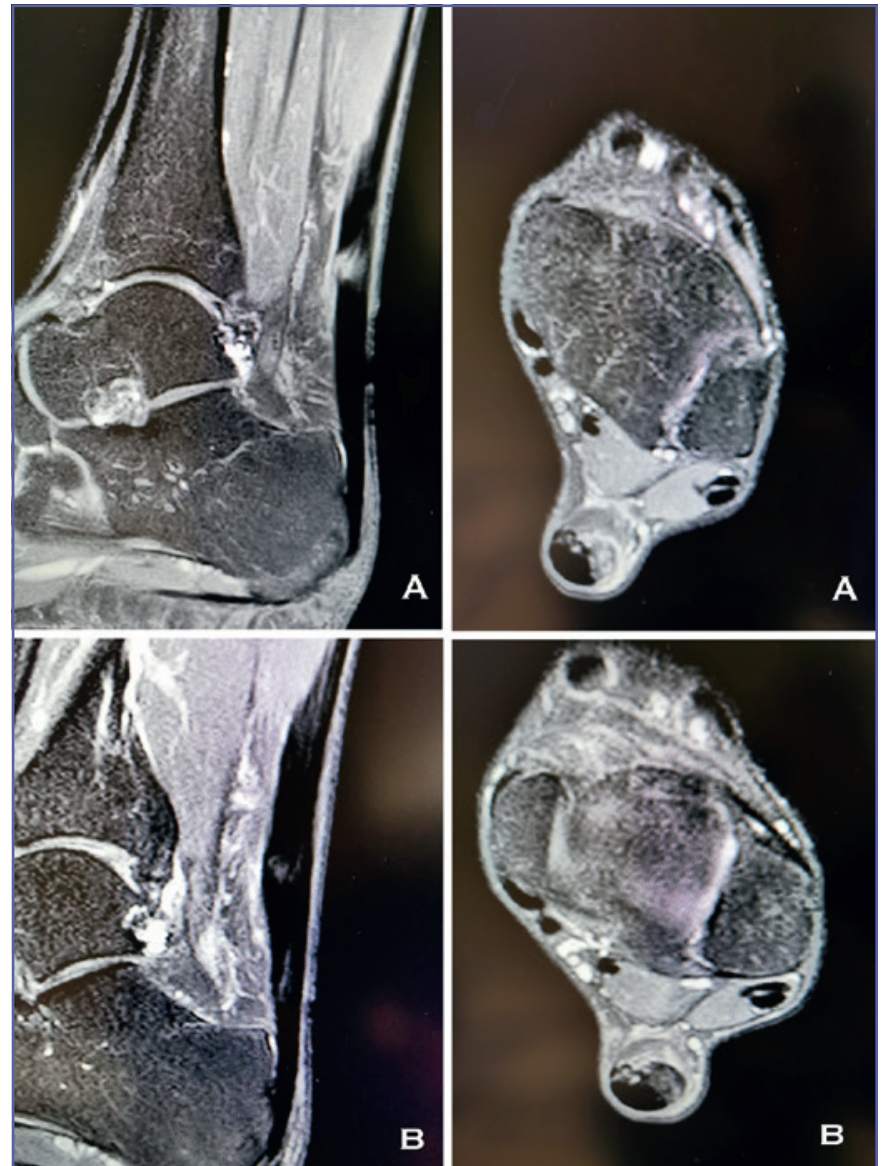

Figure 1. A) partial lesion of the right Achilles tendon (NMR image); B) right Achilles tendon at 2 months after the injection of a PB-MNC concentrate (NMR image).

proliferation and activate the apoptosis of fibro/adipogenic progenitors (FAPs, namely stromal cells capable of becoming fibroblasts or adipocytes), thus promoting regenerative wound healing and inhibiting fibrotic processes ${ }^{59}$. Monocytes can therefore reduce the number of local FAPs and can also inhibit their differentiation into adipocytes, which usually occurs in chronic muscle disorders ${ }^{60}$.

In the following stage of muscle wound healing, M1-like macrophages become M2-like macrophages, the latter being able to stimulate the development of myofibrils from myogenic cells ${ }^{61-64}$ and to stimulate the production of extracellular matrix ${ }^{59,65,66}$. Macrophage polarization does not passively accompany the temporal sequence of myogenic regeneration, but it can markedly influence and "drive" each step of the healing process $57,61,67,68$.

\section{Case report 2: regenerative therapies for a muscle injury}

This case report describes the use of autologous PB-MNCs in the treatment of a muscle lesion (Fig. 2).
Patient's general characteristics: male, 22 years old, active lifestyle (competitive athlete - triple jump).

History: the patient reported the occurrence of pain in his left femoral biceps during a training session. The symptom did not resolve in the following days and the subject decided to seek medical advice. The patient had no relevant comorbidities and did not report taking any medicinal drug.

Diagnosis, treatment and outcome: after clinical assessment and NMR examination, the patient was diagnosed with a traumatic muscle lesion of his left femoral biceps (Fig. 2A-C). Therefore, after obtaining the patient's informed consent, it was decided to accelerate the recovery with a local injection of autologous PB-MNCs, followed by a 2-week interruption of sports training sessions. After 3 weeks, the subject was allowed to practice cycling and swimming, and reported a progressive resolution of symptoms. Two months after treatment, before starting again with triple-jump training sessions, a follow-up NMR examination (Fig. 2D-F) was performed, which showed full healing of the traumatic lesion with no macroscopically detectable fibrosis in muscle, which is very important for competitive/professional athletes.

\section{Cartilage tissue repairing}

Synovial-released inflammatory substances can inhibit the chondro-genetic differentiation of MSCs in cartilages, and this is probably related to an excessive prevalence of M1-like macrophages in the lesion ${ }^{69-74}$. The modulation of macrophage polarization towards an anti-inflammatory M2 phenotype is of vital importance in the development of regenerative cell therapies for cartilages ${ }^{74-77}$. Recent studies have demonstrated that PB-MNCs can promote the migration of chondrocytes into damaged cartilage, thus potentially promoting its healing ${ }^{78,79}$. Furthermore, both direct contact and indirect paracrine signaling between isolated chondrocytes and PB-MNCs can increase the number and speed of chondrocyte migration into the cartilage lesion with no modification of their chondro-genic phenotype ${ }^{78,79}$. In particular, it seems that indirect paracrine signaling may be more important than cell-to-cell direct interaction in influencing chondrocyte migration. The stimulation promoted by PB-MNCs can also up-regulate some chondro-genic genes like COL2A1 and SOX977, and this is more pronounced in cases of local hypoxia. In laboratory animal models, when considering the extension of healed areas after wounds, it has been observed that PB-MNCs can better promote cartilage regeneration than $\mathrm{MSCs}{ }^{80}$, and $\mathrm{PB}-\mathrm{MNCs}$ can promote the migration and chondro-genetic differentiation of MSCs from the adipose tissue $^{81}$. In vitro experiments have confirmed these findings and have demonstrated that adipose-derived MSCs can only marginally increase the speed of chondrocyte migration, while the addition of PB-MNCs can increase the chondrocyte migration speed of up to 9-fold after 3 hours and improve the total number of MSCs up to 25 times after 24 hours ${ }^{81}$. 


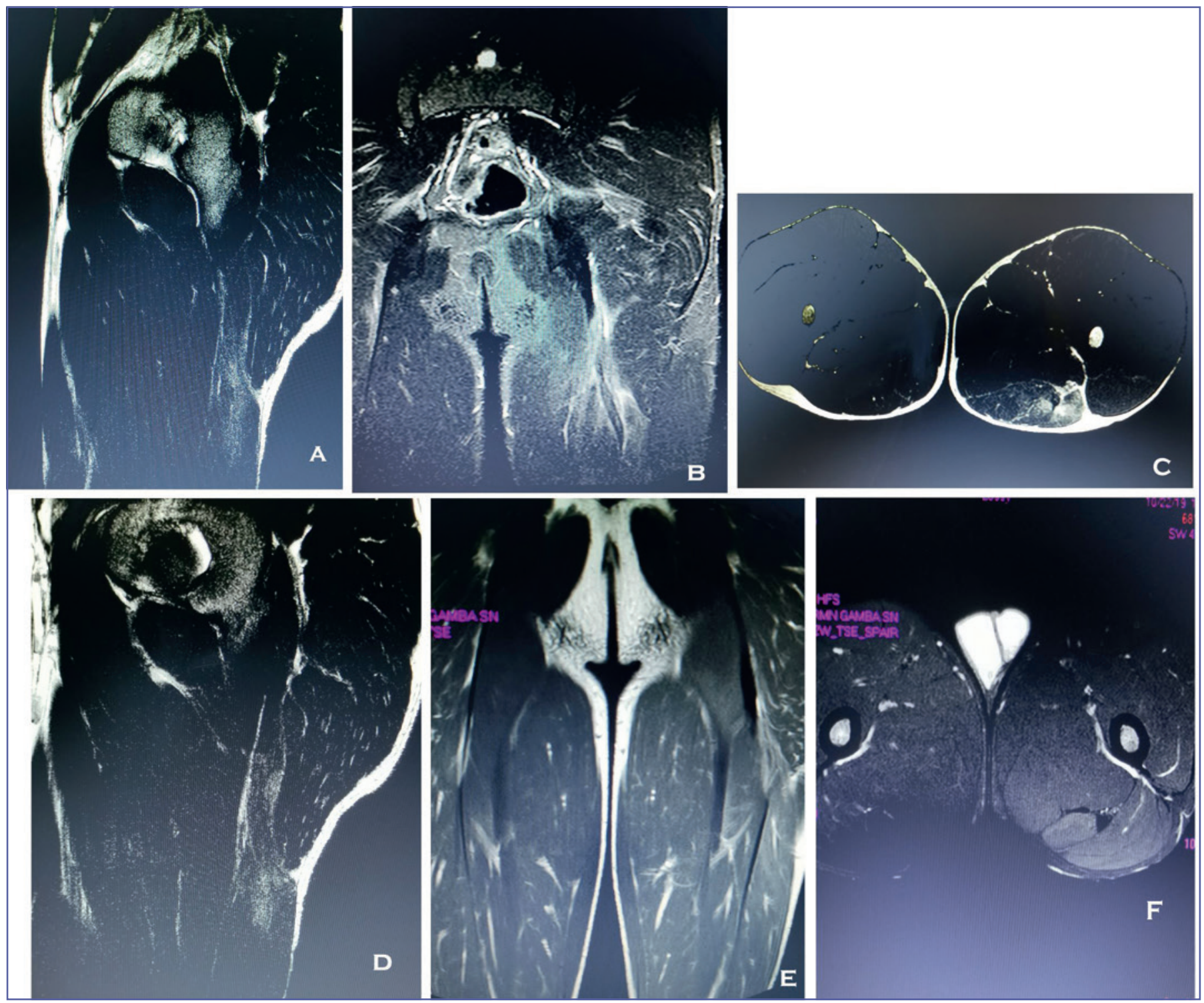

Figure 2. A-C) traumatic muscle lesion of the left femoral biceps (NMR image); D-F) two months after local injection of autologous PB-MNCs (NMR image).

\section{Critical limb ischemia and diabetic foot}

In patients with arterial diseases, two types of compensatory mechanisms usually occur as a physiological response to obstructive alterations of main arterial vessels:

- angiogenesis: the development of new capillary networks due to the sprouting of blood vessels from pre-existing capillaries in response to local hypoxia;

- arteriogenesis: when pre-existing arterioles evolve into functional collateral arteries capable of compensating the flow reduction thanks to an increase of their diameter (up to 20 times).

Monocytes and macrophages can play an important role in either the former and the latter above-mentioned processes, be- cause they release cytokines (VEGF, bFGF) ${ }^{7,82,83}$ with pro-angiogenetic properties, thus favoring blood vessel sprouting and interconnection ${ }^{84}$. Furthermore, monocytes and macrophages can interact with endothelial cells in such a way as to promote angiogenetic processes during wound healing, as demonstrated in several animal models ${ }^{85-88}$. Th1 and $\mathrm{T}_{\text {reg }}$ lymphocytes, along with natural killer cells, can synergistically interact with monocytes and increase their pro-angiogenetic activity ${ }^{89-90}$.

Lower extremity arterial disease can sometimes evolve into critical ischemia with foot ulcerations and necrosis. Several studies have indicated that pro-inflammatory M1 macrophages can be found in tissues around foot ulcerative lesions of diabetic patients: the failure of macrophages to switch from the M1-like 
to the M2-like phenotype, along with diabetic micro-angiopathy, can be responsible for chronic inflammation and, therefore, for difficulties in wound healing ${ }^{91,92}$. Additionally, it has been shown that, in smokers with diabetes and dyslipidemia at highrisk critical ischemia, the number of endothelial progenitor cells (EPC), namely a sub-population of monocytes capable of releasing pro-angiogenetic factors, can be significantly impaired ${ }^{93-95}$. Recent meta-analyses of the scientific literature suggest that, in patients with critical ischemia who have (or even have not) undergone surgical revascularization, regenerative cell therapies based on the vascular or local injection of PB-MNCs are associated with a reduction in the number of major amputations, quicker healing of ulcers, and significant improvement of trophic lesion-related pain ${ }^{96-100}$. Usually, for safe administration of PBMNCs-based therapies, patients with critical ischemia are hospitalized and the entire procedure is performed along with the ulcer surgical debridement in an equipped operatory theater with epidural or with "Bi/Tri-Block" (namely, the block of peripheral nerves) anesthesia. PB-MNCs are injected both around the ulcer and along the leg vascular axis, with each injection amounting to $0.25 \mathrm{ml}$ of concentrate. The entire therapy usually includes 3 sessions and each session takes place every 30-40 days.

\section{Case report 3: regenerative therapies for diabetic foot}

This case report describes the use of autologous PB-MNCs in the treatment of diabetic foot complications (Fig. 3).

Patient's general characteristics: male, 84 years old, sedentary lifestyle.

History: the patient reported to suffer from diabetes, hypertension, and dyslipidemia, and to regularly take insulin, oral hypoglycemic agents, antihypertensives, antiplatelet and statin drugs. The subject had a history of surgically-treated lower limb arteriopathy and developed an osteomyelitis in his fourth and fifth rays of the left foot, along with a calcaneal ulcer. Therefore, the patient underwent a trans-metatarsal amputation followed by reconstructive surgery (Fig. 3). After weeks of antibiotic therapy and advanced wound medications, the calcaneal ulcerative lesion persisted, leaving the bone exposed. Despite resorting to vacuum-assisted closure (VAC) therapy, no improvement was noticed.

Diagnosis, treatment and outcome: the patient was diagnosed with long-term and advanced complications of diabetic foot and, after obtaining informed consent, it was decided to opt for a conservative approach with a regenerative cell therapy. He was administered 4 injections of autologous PB-MNCs (once every 40 days) coupled with regular wound cleansing and surgical debridement (twice a week for 5 months) with good clinical outcome.

\section{Conclusions}

Cutting-edge research in the field of regenerative medicine is constantly advancing, but a gap between actual potentials of existing therapies and clamed benefits of some marketed products exists. In this regard, Professor Giulio Cossu, in his popular book entitled The fabric of life (La trama della vita, Marsilio Editore, 2018), stated that the present turning point and rapid evolution of regenerative medicine is unfortunately "tainted" by some biomedical corporations that have abandoned evidence-based medicine and have reverted to an old ex-adjuvantibus approach for profit maximization. Therefore, the risk of inappropriate overuse of available regenerative therapies is considerable, with high costs for both patients and healthcare systems, as well as with negligible-to-poor clinical outcomes if evidence-based indications are not followed. It is important to carry out further studies in order to better investigate the actual benefits and limitations of regenerative therapies, and to formulate a list of evidence-based indications and contraindications to optimize their use in clinical practice.

In the light of available scientific evidence regarding the process of tissue regeneration, some key points should be highlighted:

- inflammation control is fundamental in determining the efficacy of regenerative therapies, because some inflammatory processes can inhibit local MSCs;

- although injecting stem cells into damaged tissues appears to be a promising therapeutic approach, the regenerative potential of stem cells is influenced by the local immune response and, in particular, by macrophages;

- monocytes and macrophages are "key players" of the regenerative response, since they have not only a scavenger function in damaged or necrotic tissues, but hey also coordinate tissue repair, promote angiogenesis, stimulate local stem cells, and produce growth factors.

- In consideration of available evidence, the use of PB-MNCs can be promising in some ankle and foot diseases as an adjuvant/integrative strategy to improve surgical outcomes and to avoid surgery in selected patients, as demonstrated in the three case reports described herein.

\section{Ethical consideration}

This study was conducted in accordance with the Declaration of Helsinki. Full informed consent was obtained from all involved patients on a voluntary basis. Data were completely anonymized to prevent any harm or stygma. As a short collection of three case reports, this research was considered exempt from Ethics Committee approval. The literature review did not require any Ethics clearance too.

\section{Acknowledgement}

We would like to acknowledge Dr. Laura Rehak for her kind help with drafting the manuscript. 

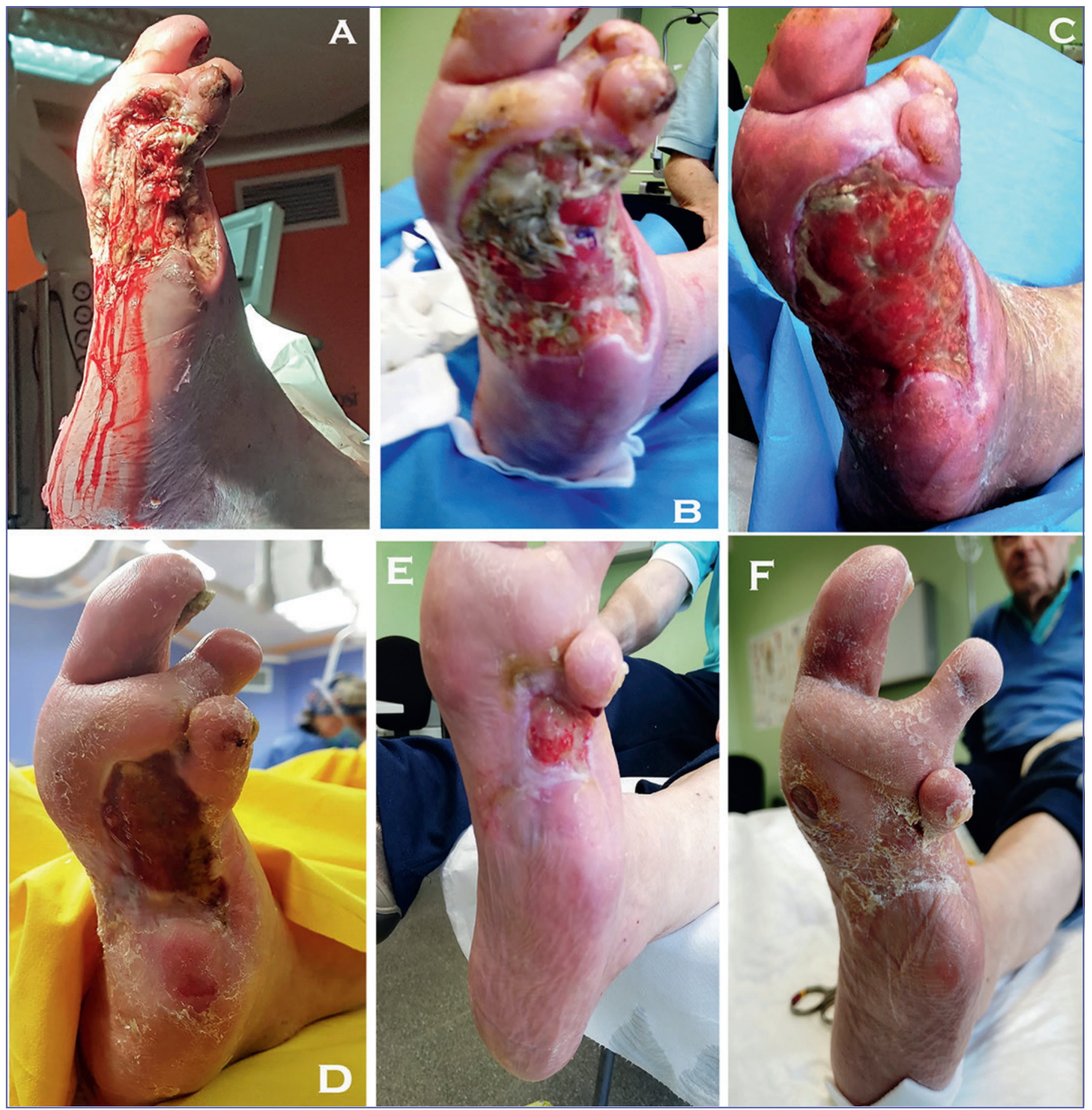

Figure 3. A) trans-metatarsal amputation of the fourth and fifth rays of the left foot with large loss of substance; B) 1 month after the first injection of PB-MNCs; C) 4 months after amputation (at the time of the third PB-MNC injection): note the well-represented granulation tissue; D) at the time of the fourth PB-MNC injection (40 days after Picture $3 C$ ): progressive regeneration of the cutaneous epithelium initiated; E) 2 weeks after the fourth injection; F) 4 weeks after the fourth injection. 


\section{Funding}

This study was not funded.

\section{Conflict of interest}

No conflict of interest was disclosed by the authors.

\section{Author contributions}

Conceptualization, F.C., M.A. and F.D.; Methodology, F.C., M.A. and F.D.; Validation, F.C., M.A. and F.D.; Investigation, F.C., M.A. and F.D.; Resources, F.C., M.A. and F.D.; Data Curation, F.C., M.A. and F.D.; Writing - Original Draft Preparation, F.C., M.A. and F.D.; Writing - Review and Editing, F.C., M.A. and F.D.; Visualization, F.C., M.A. and F.D.; Supervision, F.C., M.A. and F.D.; Project Administration, M.A.

\section{References}

1 Forbes SJ, Rosenthal N. Preparing the ground for tissue regeneration: from mechanism to therapy. Nat Med 2014;20:857-869. https://doi.org/10.1038/nm.3653

2 Wynn TA, Vannella KM. Macrophages in tissue repair, regeneration, and fibrosis. Immunity 2016;44:450-462. https://doi. org/10.1016/j.immuni.2016.02.015

3 Naik S, Larsen SB, Cowley CJ, et al. Leading edge two to tango: dialog between immunity and stem cells in health and disease. Cell 2018;175:908-920. https://doi.org/10.1016/j.cell.2018.08.071

4 Sica A, Mantovani A. Macrophage plasticity and polarization: in vivo veritas. J Clin Invest 2012;122. https://doi.org/10.1172/ JCI59643

5 Beer L, Mildner M, Gyöngyösi M, et al. Peripheral blood mononuclear cell secretome for tissue repair. Apoptosis 2016;21:13361353. https://doi.org/10.1007/s10495-016-1292-8

6 Willenborg S, Eming SA. Macrophages-sensors and effectors coordinating skin damage and repair. JDDG - J Ger Soc Dermatology 2014;12:214-221. https://doi.org/10.1111/ddg.12290

7 Zajac E, Schweighofer B, Kupriyanova TA, et al. Angiogenic capacity of M1- and M2-polarized macrophages is determined by the levels of TIMP-1 complexed with their secreted proMMP-9. Blood 2013;122:4054-4067. https://doi.org/10.1182/ blood-2013-05-501494

8 Kim H, Wang SY, Kwak G, et al. H. exosome-guided phenotypic switch of M1 to M2 macrophages for cutaneous wound healing. Adv Sci 2019;6:1900513. https://doi.org/10.1002/ advs.201900513

9 Valadi H, Ekström K, Bossios A, et al. Exosome-mediated transfer of mRNAs and microRNAs is a novel mechanism of genetic exchange between cells. Nat Cell Biol 2007;9:654-659. https:// doi.org/10.1038/NCB1596

10 Pajarinen J, Lin T, Gibon E, et al. Mesenchymal stem cell-macrophage crosstalk and bone healing. Biomaterials 2019;196:8089. https://doi.org/10.1016/j.biomaterials.2017.12.025

11 Julier Z, Park AJ, Briquez PS, et al. Promoting tissue regeneration by modulating the immune system. Acta Biomater 2017;53:1328. https://doi.org/10.1016/j.actbio.2017.01.056

12 Franchini M, Cruciani M, Mengoli C, et al. Efficacy of platelet-rich plasma as conservative treatment in orthopaedics: a sys- tematic review and meta-analysis. Blood Transfus 2018;16:502513. https://doi.org/10.2450/2018.0111-18

13 Parker AM, Katz AJ. Adipose-derived stem cells for the regeneration of damaged tissues. Expert Opin Biol Ther 2006;6:567-578. https://doi.org/10.1517/14712598.6.6.567

14 Zuk PA, Zhu MIN, Mizuno H, et al. Multilineage cells from human adipose tissue: implications for cell-based therapies. Tissue Eng 2001;7:211-229. https://doi.org/10.1089/107632701300062859

15 Im G Il, Shin YW, Lee KB. Do adipose tissue-derived mesenchymal stem cells have the same osteogenic and chondrogenic potential as bone marrow-derived cells? Osteoarthr Cartil 2005;13:845853. https://doi.org/10.1016/j.joca.2005.05.005

16 Dragoo JL, Guzman RA. Evaluation of the consistency and composition of commercially available bone marrow aspirate concentrate systems. Orthop J Sport Med 2020;8: 2325967119893634. https://doi.org/10.1177/2325967119893634

17 Kang WC, Oh PC, Lee K, et al. Increasing injection frequency enhances the survival of injected bone marrow derived mesenchymal stem cells in a critical limb ischemia animal model. Korean J Physiol Pharmacol 2016;20:657-667. https://doi.org/10.4196/ kjpp.2016.20.6.657

18 Molavi B, Zafarghandi MR, Aminizadeh E, et al. Safety and efficacy of repeated bone marrow mononuclear cell therapy in patients with critical limb ischemia in a pilot randomized controlled trial. Arch Iran Med 2016;19:388-396. https://doi.org/0161906/ AIM.004

19 Bourin P, Bunnell BA, Casteilla L, et al. Stromal cells from the adipose tissue-derived stromal vascular fraction and culture expanded adipose tissue-derived stromal/stem cells: a joint statement of the International Federation for Adipose Therapeutics and Science (IFATS) and the International So. Cytotherapy 2013;15:641-648. https://doi.org/10.1016/j.jcyt.2013.02.006

20 Astori G, Vignati F, Bardelli S, et al. "In vitro" and multicolor phenotypic characterization of cell subpopulations identified in fresh human adipose tissue stromal vascular fraction and in the derived mesenchymal stem cells. J Transl Med 2007;5:55. https:// doi.org/10.1186/1479-5876-5-55

21 Spaltro G, Straino S, Gambini E, et al. Characterization of the Pall Celeris system as a point-of-care device for therapeutic angiogenesis. Cytotherapy 2015;17:1302-1313.

22 De Angelis B, Gentile P, Orlandi F, et al. Limb rescue: a new autologous-peripheral blood mononuclear cells technology in critical limb ischemia and chronic ulcers. Tissue Eng Part C Methods 2015;21:423-435. https://doi.org/10.1089/ten.tec.2014.0245

23 Persiani F, Paolini A, Camilli D, et al. Peripheral blood mononuclear cells therapy for treatment of lower limb ischemia in diabetic patients: a single-center experience. Ann Vasc Surg 2018;53:190196. https://doi.org/10.1016/j.avsg.2018.05.036

24 Rigato M, Monami M, Fadini GP. Autologous cell therapy for peripheral arterial disease: systematic review and meta-analysis of randomized, nonrandomized, and noncontrolled studies. Circ Res 2017;120:1326-1340. https://doi.org/10.1161/ CIRCRESAHA.116.309045

25 Dubský M, Jirkovská A, Bem R, et al. Cell therapy of critical limb ischemia in diabetic patients - state of art. Diabetes Res Clin Pract 2017;126:263-271. https://doi.org/10.1016/j.diabres.2017.02.028

26 Dubsky M, Jirkovska A, Bem R, et al. Both autologous bone marrow mononuclear cell and peripheral blood progenitor cell therapies similarly improve ischaemia in patients with diabetic foot 
in comparison with control treatment. Diabetes Metab Res Rev 2013;29:369-376. https://doi.org/10.1002/dmrr.2399

27 Di Pardo A, Cappello E, Pepe G, et al. Infusion of autologous-peripheral blood mononuclear cells: a new approach for limb salvage in patients with diabetes. $7^{\text {th }}$ Int Diabet Foot Congr Abu Dhabi, IFD Congress Abu Dhabi, 4-8 December 2017:2017, p. International Diabetic Foot Congress Abu Dhabi 4-8.

28 Caravaggi CMF, Panunzi A, Sangalli E SG. Clinical outcome of autologous PB-MNC in treatment of non infected ischemic DFU (3C TUC) in non option CLI. $6^{\text {th }}$ World Union Wound Heal Soc, 2020.

29 Colonna MR, Flavia L, Gabriele D, et al. Regenerative approaches regenerative in wound healing: new alternatives for older tools. In: Intech Open, Ed. Wound Heal. New Insight into Anc. Challenges, Intech; 2016, pp. 155-163. https://doi.org/10.5772/64133

30 Gibon E, Lu LY, Nathan K, et al. Inflammation, ageing, and bone regeneration. J Orthop Transl 2017;10:28-35. https://doi. org/10.1016/j.jot.2017.04.002

31 Gallo J, Raska M, Kriegova E, et al. Inflammation and its resolution and the musculoskeletal system 2017;10:52-67. https://doi. org/10.1016/j.jot.2017.05.007

32 Feehan J, Nurgali K, Apostolopoulos V, et al. Circulating osteogenic precursor cells: building bone from blood 2018;39:603-611. https://doi.org/10.1016/j.ebiom.2018.11.051

33 Baht GS, Vi L, Alman BA. The role of the immune cells in fracture healing. Curr Osteoporos Rep 2018;16-138-145. https://doi. org/10.1007/s11914-018-0423-2

34 Batoon L, Millard SM, Wullschleger ME, et al. CD169 + macrophages are critical for osteoblast maintenance and promote intramembranous and endochondral ossification during bone repair. Biomaterials 2019;196:51-66. https://doi.org/10.1016/j. biomaterials.2017.10.033

35 Trejo I, Kojouharov H, Chen-Charpentier B. Modeling the macrophage-mediated inflammation involved in the bone fracture healing process. Math Comput Appl 2019;24:12. https://doi. org/10.3390/mca24010012

36 Ogle ME, Segar CE, Sridhar S, et al. Monocytes and macrophages in tissue repair: implications for immunoregenerative biomaterial design. Exp Biol Med 2016;241:1084-1097. https://doi. org/10.1177/1535370216650293

37 Loi F, Córdova LA, Pajarinen J, et al. Inflammation, fracture and bone repair. Bone 2016;86:11-130. https://doi.org/10.1016/j. bone.2016.02.020

38 Tsukasaki M, Takayanagi H. Osteoimmunology: evolving concepts in bone - immune interactions in health and disease. Nat Rev Immunol 2019;19:626-642. https://doi.org/10.1038/ s41577-019-0178-8

39 Henrich D, Seebach C, Verboket R, et al. The osteo-inductive activity of bone-marrow-derived mononuclear cells resides within the CD14+ population and is independent of the CD34+ population. Eur Cells Mater 2018;35:165-177. https://doi.org/10.22203/ eCM.v035a12

40 Champagne CM, Takebe J, Offenbacher S, et al. Macrophage cell lines produce osteoinductive signals that include bone morphogenetic protein-2. Bone 2002;30:26-31. https://doi.org/10.1016/ s8756-3282(01)00638-x

41 Pirraco RP, Reis RL, Marques AP. Effect of monocytes/macrophages on the early osteogenic differentiation of hBMSCs 2012;7:392-400. https://doi.org/10.1002/term
42 Könnecke I, Serra A, El Khassawna T, et al. T and B cells participate in bone repair by infiltrating the fracture callus in a twowave fashion. Bone 2014;64:155-165. https://doi.org/10.1016/j. bone.2014.03.052

43 Nathan K, Lu LY, Lin T, et al. Precise immunomodulation of the M1 to M2 macrophage transition enhances mesenchymal stem cell osteogenesis and differs by sex. Bone Joint Res 2019;8:481489. https://doi.org/10.1302/2046-3758.810.BJR-2018-0231.R2

44 Saldaña L, Vallés G, Bensiamar F, et al. Paracrine interactions between mesenchymal stem cells and macrophages are regulated by 1,25-dihydroxyvitamin D3. Scientific Reports 2017;Nov 3. https://doi.org/10.1038/s41598-017-15217-8ß [Epub Ahead of Print]

45 Saldaña L, Bensiamar F, Vallés G, et al. Immunoregulatory potential of mesenchymal stem cells following activation by macrophage-derived soluble factors. Stem Cell Res Ther 2019;Feb 13. https://doi.org/10.1186/s13287-019-1156-6 [Epub Ahead of Print]

46 Vallés G, Bensiamar F, Maestro-Paramio L, et al. Influence of inflammatory conditions provided by macrophages on osteogenic ability of mesenchymal stem cells. Stem Cell Res Ther 2020;11:57. https://doi.org/10.1186/s13287-020-1578-1

47 Schlundt C, Khassawna T El, Serra A, et al. Macrophages in bone fracture healing: their essential role in endochondral ossification. Bone 2018;106:78-89. https://doi.org/10.1016/j. bone.2015.10.019

48 Sugg KB, Lubardic J, Gumucio JP, et al. Changes in macrophage phenotype and induction of epithelial-to- mesenchymal transition genes following acute Achilles tenotomy and repair 2017:944951. https://doi.org/10.1002/jor.22624

49 Dakin SG, Martinez FO, Yapp C, et al. Inflammation activation and resolution in human tendon disease. Sci Transl Med 2015;7:311ra173. https://doi.org/10.1126/scitranslmed.aac4269

50 Chisari Em, Rehak L, Khan WS, et al. Tendon healing in presence of chronic low level inflammation. Br Med Bull 2019;132:97-116. https://doi.org/10.1093/bmb/ldz035

51 Chisari E, Rehak L, Khan WS, et al. The role of the immune system in tendon healing: a systematic review. Br Med Bull 2020;133:49-64. https://doi.org/10.1093/bmb/ldz040

52 Arnold L, Henry A, Poron F, et al. Inflammatory monocytes recruited after skeletal muscle injury switch into antiinflammatory macrophages to support myogenesis. J Exp Med 2007;204:10571069. https://doi.org/10.1084/jem.20070075

53 Novak ML, Weinheimer-Haus EM, Koh TJ. Macrophage activation and skeletal muscle healing following traumatic injury. J Pathol 2014;232:344-355. https://doi.org/10.1002/path.4301

54 Schiaffino S, Pereira MG, Ciciliot S, et al. Regulatory T cells and skeletal muscle regeneration. FEBS J 2017;284:517-524. https:// doi.org/10.1111/febs.13827

55 Wang H, Melton DW, Porter L, et al. Altered macrophage phenotype transition impairs skeletal muscle regeneration. Am J Pathol 2014;184:1167-1184. https://doi.org/10.1016/j. ajpath.2013.12.020

56 Tidball JG, Welc SS. Macrophage-derived IGF-1 is a potent coordinator of myogenesis and inflammation in regenerating muscle. Mol Ther 2015;23:1134-1135. https://doi.org/10.1038/ mt.2015.97

57 Ceafalan LC, Fertig TE, Popescu AC, et al. Skeletal muscle regeneration involves macrophage-myoblast bonding. Cell Adhes 
Migr 2018;12:228-235. https://doi.org/10.1080/19336918.2017. 1346774

58 Chazaud B, Sonnet C, Lafuste P, et al. Satellite cells attract monocytes and use macrophages as a support to escape apoptosis and enhance muscle growth. J Cell Biol 2003;163:1133-1143. https:// doi.org/10.1083/jcb.200212046

59 Juban G, Chazaud B. Metabolic regulation of macrophages during tissue repair: insights from skeletal muscle regeneration. FEBS Lett 2017;591:3007-3021. https://doi.org/10.1002/1873-3468.12703

60 Juban G, Chazaud B. Metabolic regulation of macrophages during tissue repair: insights from skeletal muscle regeneration. FEBS Lett 2017;591:3007-3021. https://doi.org/10.1002/1873-3468.12703

61 Dort J, Fabre P, Molina T, et al. Macrophages are key regulators of stem cells during skeletal muscle regeneration and diseases. Stem Cells Int 2019;2019:1-20. https://doi.org/10.1155/2019/4761427

62 Wang X, Zhao W, Ransohoff RM, et al. Infiltrating macrophages are broadly activated at the early stage to support acute skeletal muscle injury repair. J Neuroimmunol 2018;317:55-66. https:// doi.org/10.1016/j.jneuroim.2018.01.004

63 Qiu X, Liu S, Zhang H, et al. Mesenchymal stem cells and extracellular matrix scaffold promote muscle regeneration by synergistically regulating macrophage polarization toward the M2 phenotype. Stem Cell Res Ther 2018;9:2-15. https://doi.org/10.1186/ s13287-018-0821-5

64 Novak ML, Weinheimer-Haus EM, Koh TJ. Macrophage activation and skeletal muscle healing following traumatic injury. J Pathol 2014;232:344-355. https://doi.org/10.1002/path.4301

65 Rahmani W, Sinha S, Biernaskie J. Immune cell - stem cell cooperation. The Scientist 2016;Jul 1. [Epub Ahead of Print]

66 Juhas M, Abutaleb N, Wang JT, et al. Incorporation of macrophages into engineered skeletal muscle enables enhanced muscle regeneration. Nat Biomed Eng 2018;2:942. https://doi.org/10.1038/ s41551-018-0290-2

67 Baht GS, Bareja A, Lee DE, et al. Meteorin-like facilitates skeletal muscle repair through a Stat3/IGF-1 mechanism. Nat Metab 2020;2:278-289. https://doi.org/10.1038/s42255-020-0184-y

68 Arnold L, Henry A, Poron F, et al. Inflammatory monocytes recruited after skeletal muscle injury switch into antiinflammatory macrophages to support myogenesis. J Exp Med 2007;204:10571069. https://doi.org/10.1084/jem.20070075

69 Fahy N, de Vries-van Melle ML, Lehmann J, et al. Human osteoarthritic synovium impacts chondrogenic differentiation of mesenchymal stem cells via macrophage polarisation state. Osteoarthr Cartil 2014;22:1167-1175. https://doi.org/10.1016/j. joca.2014.05.021

70 Fernandes TL, Gomoll AH, Lattermann C, et al. Macrophage: a potential target on cartilage regeneration. Front Immunol 2020;Feb 11. https://doi.org/10.3389/fimmu.2020.00111 [Epub Ahead of Print]

71 Griffin T, Scanzello A. Macrophages in OA. Clin Exp Rheumatol 2019;37:s57-63.

72 Xie J, Huang Z, Yu X, et al. The macrophage in knee osteoarthritis:e and clinical implications. Cytokine Growth Factor Rev 2019;46:36-44. https://doi.org/10.1016/j.cytogfr.2019.03.004

73 Hm Berkelaar M, Korthagen NM, Jansen G, et al. Synovial macrophages: potential key modulators of cartilage dam-age, osteophyte formation and pain in knee osteoarthritis. J Rheum Dis Treat 2018;4:59. https://doi.org/10.23937/2469-5726/1510059
74 Liu B, Zhang M, Zhao J, et al. Imbalance of M1/M2 macrophages is linked to severity level of knee osteoarthritis. Exp Ther Med 2018;16:5009-5014. https://doi.org/10.3892/etm.2018.6852

75 Misharin AV, Cuda CM, Budinger GRS, et al. Nonclassical Ly6C(-) monocytes drive the development of inflammatory arthritis in mice. Cell Rep 2014;9:591-604. https://doi.org/10.1016/j. celrep.2014.09.032

76 Gómez-Aristizábal A, Gandhi R, Mahomed NN, et al. Synovial fluid monocyte/macrophage subsets and their correlation to patient-reported outcomes in osteoarthritic patients: a cohort study. Arthritis Res Ther 2019;21:26. https://doi.org/10.1186/ s13075-018-1798-2

77 Ardura JA, Rackov G, Izquierdo E, et al. Targeting macrophages: friends or foes in disease? Front Pharmacol 2019;10:1255. https:// doi.org/10.3389/fphar.2019.01255

78 Onuora S. PBMCs stimulate chondrocyte migration and cartilage repair PBMCs stimulate chondrocyte migration and cartilage repair. Nat Publ Gr 2015. https://doi.org/10.1038/nrrheum.2015.118

79 Hopper N, Henson F, Brooks R, et al. Peripheral blood derived mononuclear cells enhance osteoarthritic human chondrocyte migration. Arthritis Res Ther 2015:1-10. https://doi.org/10.1186/ s13075-015-0709-z

80 Hopper N, Wardale J, Brooks R, et al. Peripheral blood mononuclear cells enhance cartilage repair in vivo osteochondral defect model. PLos One 2015:1-16. https://doi.org/10.1371/journal. pone. 0133937

81 Hopper N, Wardale J, Howard D, et al. Peripheral blood derived mononuclear cells enhance the migration and chondrogenic differentiation of multipotent mesenchymal stromal. Cells 2015;2015. https://doi.org/10.1155/2015/323454

82 Awad O. Differential healing activities of CD34+ and CD14+ endothelial cell progenitors. Arterioscler Thromb Vasc Biol 2006;26:758-764. https://doi.org/10.1161/01. ATV.0000203513.29227.6f

83 Lopes-Coelho S, Gouveia-Fernandes M, Lopes D, et al. Monocytes as Endothelial Progenitor Cells (EPCs), another brick in the wall to disentangle tumor angiogenesis. Cells 2020;9:107. https:// doi.org/10.3390/cells9010107

84 Fantin A, Vieira JM, Gestri G, et al. Tissue macrophages act as cellular chaperones for vascular anastomosis downstream of VEGF-mediated endothelial tip cell induction. Blood 2010;116:829-840. https://doi.org/10.1182/blood-2009-12-257832

85 Seaman SA, Cao Y, Campbell CA, et al. Macrophage recruitment and polarization during collateral vessel remodeling in murine adipose tissue. Microcirculation 2016;23:75-87. https://doi. org/10.1111/micc.12261

86 Baer C, Squadrito ML, Iruela-Arispe ML, et al. Reciprocal interactions between endothelial cells and macrophages in angiogenic vascular niches. Exp Cell Res 2013;319:1626-1634. https://doi. org/10.1016/j.yexcr.2013.03.026

87 Krishnasamy K, Limbourg A, Kapanadze T, et al. Blood vessel control of macrophage maturation promotes arteriogenesis in ischemia. Nat Commun 2017;8:952. https://doi.org/10.1038/ s41467-017-00953-2

88 Pipp F, Heil M, Issbrücker K, et al. VEGFR-1-selective VEGF homologue PlGF is arteriogenic: evidence for a monocyte-mediated mechanism. Circ Res 2003;92:378-385. https://doi. org/10.1161/01.RES.0000057997.77714.72 
89 Zouggari Y, Ait-Oufella H, Waeckel L, et al. Regulatory $\mathrm{T}$ cells modulate postischemic neovascularization. Circulation 2009;120:1415-1425. https://doi.org/10.1161/ CIRCULATIONAHA.109.875583

90 Silvestre J-S, Mallat Z, Tedgui A, et al. Post-ischaemic neovascularization and inflammation. Cardiovasc Res 2008;78:242-249. https://doi.org/10.1093/cvr/cvn027

91 Miao M, Niu Y, Xie T, et al. Diabetes-impaired wound healing and altered macrophage activation: a possible pathophysiologic correlation. Wound Repair Regen 2012;20:203-213. https://doi. org/10.1111/j.1524-475X.2012.00772.x

92 Yan J, Tie G, Wang S, et al. Diabetes impairs wound healing by Dnmt1-dependent dysregulation of hematopoietic stem cells differentiation towards macrophages. Nat Commun 2018; Jan 2. https://doi.org/10.1038/s41467-017-02425-z [Epub Ahead of Print]

93 Rehman J, Li J, Orschell CM, et al. Peripheral blood "endothelial progenitor cells" are derived from monocyte/macrophages and secrete angiogenic growth factors. Circulation 2003;107:11641169. https://doi.org/10.1161/01.CIR.0000058702.69484.A0

94 Imanishi T, Hano T, Sawamura T, et al. Oxidized low-density lipoprotein induces endothelial progenitor cell senescence, leading to cellular dysfunction. Clin Exp Pharmacol Physiol 2004;31:407413. https://doi.org/10.1111/j.1440-1681.2004.04022.x

95 Kondo T, Hayashi M, Takeshita K, et al. Smoking cessation rapidly increases circulating progenitor cells in peripheral blood in chronic smokers. Arterioscler Thromb Vasc Biol 2004;24:14421447. https://doi.org/10.1161/01.ATV.0000135655.52088.c5

96 Guo J, Dardik A, Fang K, et al. Meta-analysis on the treatment of diabetic foot ulcers with autologous stem cells. Stem Cell Res Ther 2017;8:228. https://doi.org/10.1186/s13287-017-0683-2

97 Xie B, Luo H, Zhang Y, et al. Autologous stem cell therapy in critical limb ischemia : a meta-analysis of randomized controlled trials. Stem Cells Int 2018:2-11.

98 Ai M, Yan CF, Xia FC, et al. Safety and efficacy of cell-based therapy on critical limb ischemia: a meta-analysis. Cytotherapy 2016;18:712-724. https://doi.org/10.1016/j.jcyt.2016.02.009

99 Liew A, Bhattacharya V, Shaw J, et al. Cell therapy for critical limb ischemia. Angiology 2016;67:444-455. https://doi. org/10.1177/0003319715595172

100 Jiang $\mathrm{X}$, Zhang $\mathrm{H}$, Teng $\mathrm{M}$. Effectiveness of autologous stem cell therapy for the treatment of lower extremity ulcers. Medicine (Baltimore) 2016;95:1-8. https://doi.org/10.1097/ MD.0000000000002716 